\title{
Sokak Aydınlatması Dönüşümü Fayda Maliyet Analizi Üzerine Bir Mühendislik Ekonomisi Çalışması
}

\author{
Emre YILMAZ ${ }^{*}$,a , Orhan ERDEN ${ }^{\mathrm{a}}$, Nuri Yunus KOCADAĞ ${ }^{\mathrm{b}}$

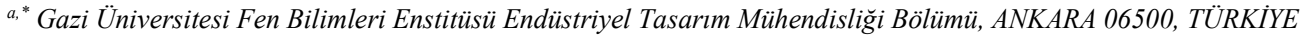 \\ $b^{*}{ }^{*}$ Bingöl Üniversitesi Teknik Bilimler MYO Elektrik ve Enerji Bölümü, BİNGÖL 12000, TÜRKIYYE
}

\section{MAKALE \\ BİLGİİ \\ Alınma: 05.12.2019 \\ Kabul: 27.12.2019 \\ Anahtar Kelimeler: \\ Sokak aydınlatması, \\ Yol aydınlatmasi, \\ LED aydinlatma, \\ LED armatür, \\ LED sokak armatürü \\ 'Sorumlu Yazar: \\ e-posta: \\ emre.yilmaz@aydinlat \\ ma.org}

\section{ÖZET}

Aydınlatma teknolojileri geliştikçe daha verimli aydınlatma aygıtları geliştirilmiştir. Mevcut durumda kullanılan geleneksel aydınlatma sistemlerinin yeni teknolojilerle değiştirilmesiyle enerji tasarrufu sağlanacağı açıktır. Bu kapsamda ülkemizde sokak aydınlatmalarında uzun yıllar boyunca kullanılan geleneksel aydınlatma armatürlerinin LED aydınlatma armatürleriyle dönüşümü planlanmaktadır. LED aydınlatma sistemleri, geleneksel aydınlatmalara göre daha verimli ve daha uzun ömürlüdür. Bu sayede ciddi bir tasarruf sağlayacağı söylenebilir. LED teknolojisi gün geçtikçe ucuzlasa da milyonlarca sokak lambasının LED dönüşümü için hala büyük bir harcama yapılması gerekmektedir. Bu çalışma kapsamında ülkemizde yapılması planlanan sokak aydınlatması dönüşümünün 5 yıllık fayda maliyet analizi gerçekleştirilmiştir.

https://dx.doi.org/10.30855/gmbd.2019.03.09

\section{An Engineering Economy Study on Cost-Benefit Analysis of Street Lighting Transformation}

\section{ARTICLE \\ INFO \\ Received: 05.12.2019 \\ Accepted: 27.12.2019 \\ Keywords: \\ Street lighting, \\ Road lighting, \\ LED lighting, \\ LED luminaire, \\ LED street light

\begin{tabular}{l} 
"Corresponding \\
\hline Authors \\
e-mail: \\
emre.yilmaz@aydinlat \\
ma.org
\end{tabular}

\begin{abstract}
As lighting technologies have evolved, more efficient lighting devices have been developed. It is clear that energy saving can be achieved by replacing the currently used traditional lighting systems with new technologies. It is planned to transform traditional lighting fixtures used in street lighting for many years with LED lighting fixtures in our country. LED lighting systems are more efficient and last longer than traditional lighting. In this way, it can be said that it will provide significant savings. Even though LED technology is getting cheaper every day, there is still a huge expense for the LED conversion of millions of street lamps. Within the scope of this study, a 5year cost-benefit analysis of the street lighting transformation planned to be performed in our country was performed.
\end{abstract}

https://dx.doi.org/10.30855/gmbd.2019.03.09 


\section{GIRISŞ (INTRODUCTION)}

İnsanoğlu, aydınlatma ihtiyacını binlerce yıldır farkı yollarla karşılamaktadır. Güneş ışığı, ateş, mum ve akkor filaman lambalar gibi 1şığın doğal yolla elde edilmesinin sonrasında floresan ve LED teknolojisine geçiş yapılmıştır. Yeni gelen her teknoloji bir önceki teknolojiyle kıyaslandığında pek çok avantaja sahiptir. Her yeni teknolojide öne çıkan ve bu teknolojilerin kolayca benimsenmesini sağlayan özellik ise 1 şık verimidir. Diğer bir deyişle, 1şık kaynaklarının birim ışığı üretmek için harcadığı enerji miktarı yeni teknolojiler yardımıyla gün geçtikçe azalmaktadır.

Işık verimi, bir aydınlatma elemanının elektrik gücünü 1şığa ne kadar verimle dönüştürdüğünü belirtir. Ișık akısının güce oranı, watt başına lümen cinsinden ifade edilir ve $1 \mathrm{~m} / \mathrm{W}$ şeklinde sembolize edilir. Işık verimi (1şık etkinliği), belirli bir miktar güç ile elde edilen aydınlatma gücünü ifade eder. Bir 1şık kaynağı, bir watt güç harcayarak kaç lümen 1şık çıktısı sunuyorsa bu 1şık verimidir.

Dünyadaki gidişat diğer teknolojilerde olduğu gibi aydınlatma armatürlerinde de daha verimli, daha uzun ömürlü, bakım gerektirmeyen, zararlı maddeler içermeyen, gelişen ve değişen teknolojiye uyumlu ve yönetilebilen LED aydınlatma sistemlerine doğru gitmektedir [1].

Günümüzde, tüm dünyada iç ve dış mekân aydınlatmalarında LED teknolojisine dönüşüm süreci yaşanmaktadır. $\mathrm{Bu}$ dönüşümün ivmelenmesinde teknolojik gelişmelere bağlı iki ana etken bulunmaktadır. Birincisi, ışık veriminin güç geçtikçe artması, ikincisi ise ürün fiyatlarının düşmesidir.

LED dönüşümünün uygulandığı alanlardan bir tanesi de sokak aydınlatmaları ya da diğer bir deyişle yol aydınlatmalarıdır. Dünyanın dört bir yanında hükümetler, belediyeler ve elektrik şirketleri enerji tüketimini ve buna bağlı giderlerini azaltmak için sokak aydınlatmalarında LED teknolojisine geçiş yapmaktadır.

Ülkemizde sokak aydınlatmalarındaki LED dönüşümü 2018 yılında açıklanan Ulusal Enerji Verimliliği Eylem Planı'na dahil edilmiştir. Bu plan dahilinde Türkiye'deki 7,5 milyon sokak lambasının yüzde 30'unun (2,25 milyon sokak lambasi) 2023 yılına kadar değiştirilmesi planlanmaktadır [2].
Sokak aydınlatmaları dönüşümüne ilişkin iki farklı görüş bulunmaktadır. Birincisi, sokak aydınlatmalarında mevcut durumda kullanılan yüksek basınçlı sodyum buharlı (YBSB) lambaların hala çok verimli ve uzun ömürlü olduğu bu sebeple dönüşümün mantıklı bir yatırım olmadığı yönündedir. Diğer bir görüş ise LED aydınlatma teknolojilerinin daha yüksek verim ve daha uzun ömür sunarak kendini kısa sürede amorti edeceği şeklindedir.

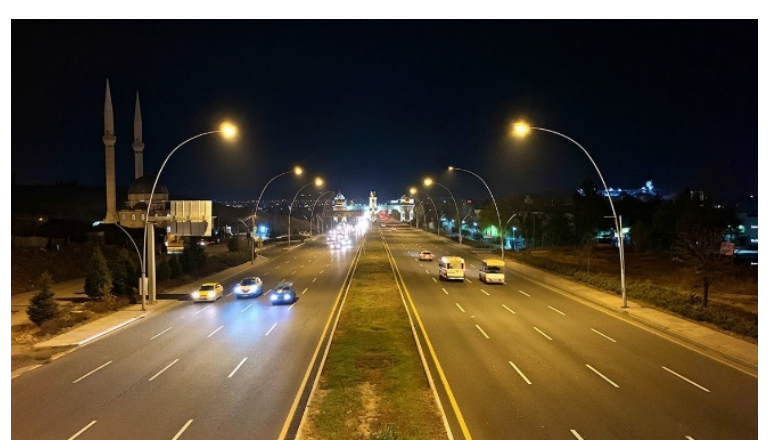

Resim 1. Ankara'da bir yol aydınlatma uygulaması $(A$ road lighting application in Ankara)

Sokak aydınlatmalarında yapılacak yenileme bir kamu yatırımıdır ve kamu yatırımları halkın faydası için yapılmalıdır. $\mathrm{Bu}$ çalışmada sokak aydınlatmalarında yapilmasi planlanan LED dönüşümünün fayda maliyet analizi gerçekleştirilerek yapılan yatırımın sağlanacak fayda ile karşılaştırması yapilacaktır.

\section{LITERATÜR ARAŞTIRMASI (LITERATURE RESEARCH)}

Hem iç hem de dış aydınlatmada enerji tasarrufunun en etkin yolu ihtiyaç duyulmayan 1 şı kaynaklarının kapatılmasıdır. 1980'lerde Japonya'da yolların aydınlatma kontrolü konsepti oluşturulmuştur. Fakat teknik imkanların yetersizliğinden dolayı gerçekleştirilememiş̧ir. LED teknolojisi bu konseptin geliştirilmesini ve uygulanmasını sağlamıştır [3].

Yol güvenliği için yapılan ergonomik araştırmalar, daha fazla güvenlik ve konforlu yol aydınlatma seçenekleri önemli hale gelmiştir [4].

$\begin{array}{llr}\text { YBSB lambalar } & 1968 \text { 'den beri } & \text { yol } \\ \text { aydınlatmalarında } & \text { kullanılmıştır. } & \text { Yol } \\ \text { aydınlatmalarında } & \text { YBSB yerine güncel aydınlatma } \\ \text { verimliliğine sahip LED'ler kullanıldığında ne kadar } \\ \text { enerji tasarrufu elde edileceğiyle ilgili } 2009 \text { yılında } \\ \text { Çin'de yapılan bir çalışma ile günün şartlarına göre } \\ \text { böyle bir değişimin çok gerekli olmadığı sonucuna }\end{array}$


ulaşılmıştır. Bu çalışmada YBSB ve LED lambaların verimlilikleri karşılaştırılmıştır. Yol aydınlatmalarında kullanılan YBSB lambaların armatür verimliliği $70.1 \mathrm{~lm} / \mathrm{W}$ ve LED lambaların $72.9 \mathrm{~lm} / \mathrm{W}$ olarak belirlenmiştir. Yakın gelecekte LED'lerin ilk maliyet, kullanım ömrü, sıcaklık ve aydınlatma verimliliklerinde yapılacak geliştirmelerle en tasarruflu 1şık kaynağı olacağı belirtilmiştir [5].

LED armatürlerde 1 şı doğrudan aşağı yönlendirilebilirken YBSB armatürleri içerisinde yansımalardan dolayı kayıplar olmakta ve 1 şı verimsiz kullanılmaktadır. Çoğu insan ay 1şı̆̆ına benzediği için dış mekân aydınlatma uygulamalarında beyaz 1şı̆̆1 tercih ettiği görülmüştür. YBSB lambaların ışıkları sarımsı yani düşük renk sıcaklığına sahipken LED lambalar yüksek renk sıcaklıklarında daha verimli bir şekilde çalışabildiği belirlenmiştir [6][7].

ABD'de bazı bölgelerde yapılan HID-LED dönüşümlerinin maliyet, ürün ömrüyle ilgili bazı örnekler verilmiştir. 2012'de Minnesota'da HID lambaların 21.000 saat, LED lambaların 78.000 saat çalışma ömürleri baz alınarak yılda 3.550 saat çalışmaya karşılık 8-12 yıl aralığında LED’e yapılan yatırımın geri ödeneceği hesaplanmıştır. 2013'te Phoenix'te 95.000 HID armatürün LED'e dönüşümüyle ilgili yapılan çalışmada 1 milyon \$ yatırımın 9 yıllık basit geri ödeme süresi ve 10 yıl ve üzeri süre zarfinda ise 5 milyon $\$$ yıllık getiri sağlayacağı hesaplanmıştır. 2016 yılında Charlotte Country'de 2145 noktada yapılacak YBSB-LED dönüşümünün maliyet analizinde 20 yıllık süre boyunca maliyetlerin yakın olduğu ancak düşen LED maliyetleriyle LED dönüşümünün daha ekonomik bir seçenek olacağı sonucuna varılmıştır [8].

Körfez Arap Ülkeleri İşbirliği Konseyi (KİK)'nin ulaşım yollarında kullanılan günlük çalışma süresi 11 saat olarak belirlenen, 1131 adet güç tüketimi 400W ve kullanım ömrü 18.000 saat olan YBSB aydınlatma armatürlerinin yerine yine aynı sayıda güç tüketimi $100 \mathrm{~W}$ ve kullanım ömrü 80.000 saat olan LED armatürleri kullanıldığında 2015-2016 yılları arasındaki fiyat tekliflerine göre 20 y1llık maliyet analizi yapılmıştır. $\mathrm{Bu}$ çalışma sonucunda yapılan dönüşümün şirkete ve doğaya yararları hesaba katılarak yıllık ortalama tasarrufun YBSB-LED dönüşümüyle oluşan toplam güç tüketimine oranı $433,36 \$ / \mathrm{kW}$ ve şirketin 20 yıl sonunda yaptığı tasarruf $\$ 4.492 .317 .72$ olarak bulunmuştur [9].

Yunanistan'ın kuzeyinde 670 km'lik bir mesafeyi kapsayan Egnatia Odos bölgesinde, sokak aydınlatmalarında kullanılan YBSB aydınlatma armatürlerinin, LED aydınlatmaya dönüşümüyle birlikte elde edilen enerji tasarrufu ve LED teknolojisinin gelişmesinin daha yakından incelenmesi amaciyla 2017 ve 2019 yıllarında kullanılan LED armatürlerle adaptif ve normal çalışma koşullarında karşılaştırmaları gerçekleştirilmiştir. Çalışma sonucunda 2019 yılında LED teknolojisindeki gelişmelerle 2017 y1lına göre adaptif ve normal kullanıma bağlı olarak enerji tasarrufunda \%13,57-\%27,93 aralığında verim artışı sağlanmıştır [10].

\section{YOL AYDINLATMA SINIFLARI (ROAD LIGHTING CLASSES)}

Yol aydınlatmalarının, aydınlatma sınıflarının belirlendiği EN 13201-1, performans özelliklerini içeren EN 13201-2, performans hesaplamalarını içeren EN 13201-3 ve aydınlatma performansını ölçme metotlarını içeren EN 13201-4 standart özelliklerini sağlaması gerekmektedir.

Uluslararası Aydınlatma Komisyonu CIE tarafından yayınlanan CIE 115:2010 teknik raporunda güç tüketiminin önemi, aydınlatma armatürlerinin parlaklık performansının geliştirilmesi, trafikte karşılaşma bölgelerinde parlaklık seviyesinin değişimi, teknoloji gelişiminin önemi gibi konulara değinilmiştir. $\mathrm{Bu}$ rapora göre yol aydınlatması sinıflandırması yapılırken motorlu araçlar M sınıfı, trafikte karşılaşma bölgeleri C sınıfı ve yayalar ile düşük hızlı trafik bölgeleri P sınıfı olarak kategorize edilmiştir. CIE 115:2010'a göre M yol aydınlatması sınıfının seçimi için aşağıdaki Tablo 1'de verilen parametreler kullanılmıştır. 
Tablo 1. Yol aydınlatma sınıfi seçim parametreleri (Road lighting class selection parameters) [11]

\begin{tabular}{|c|c|c|}
\hline Parametre & Seçenek & $\begin{array}{c}\text { Ăğırlık } \\
\text { Değeri } \\
(V w)\end{array}$ \\
\hline \multirow{3}{*}{$\mathrm{H} 1 \mathrm{z}$} & Çok Yüksek & 1 \\
\hline & Yüksek & 0.5 \\
\hline & Orta & 0 \\
\hline \multirow{5}{*}{$\begin{array}{l}\text { Trafik } \\
\text { yoğunluğu }\end{array}$} & Çok Yüksek & 1 \\
\hline & Yüksek & 0.5 \\
\hline & Orta & 0 \\
\hline & Düşük & -0.5 \\
\hline & Çok Düşük & -1 \\
\hline \multirow[t]{3}{*}{ Trafik dağılımı } & $\begin{array}{l}\text { Yüksek oranda } \\
\text { motorlu araç olmayan } \\
\text { trafikle karı̧ık }\end{array}$ & 2 \\
\hline & Karış1k & 1 \\
\hline & Sadece motorlu araç & 0 \\
\hline \multirow{2}{*}{$\begin{array}{l}\text { Yolda refüj } \\
\text { ayrımı var mı? }\end{array}$} & Hayır & 1 \\
\hline & Evet & 0 \\
\hline \multirow{2}{*}{$\begin{array}{l}\text { Kavşak } \\
\text { yoğunluğu }\end{array}$} & Yüksek & 1 \\
\hline & Orta & 0 \\
\hline \multirow{2}{*}{$\begin{array}{l}\text { Park etmiş araç } \\
\text { var mı? }\end{array}$} & Var & 0.5 \\
\hline & Yok & 0 \\
\hline \multirow{3}{*}{$\begin{array}{l}\text { Çevre } \\
\text { aydınlatması }\end{array}$} & Yüksek & 1 \\
\hline & Orta & 0 \\
\hline & Düşük & -1 \\
\hline \multirow{2}{*}{$\begin{array}{l}\text { Görsel } \\
\text { kılavuz/Trafik } \\
\text { kontrolü }\end{array}$} & Zayıf & 0.5 \\
\hline & Orta veya İyi & 0 \\
\hline
\end{tabular}

Tablo 1'de verilen parametrelere göre ağırlık değerleri toplanır ve Denklem 1 kullanılır. Eğer değer tam sayı değilse bir aşağıdaki sayıya yuvarlanarak Tablo 2'de belirtilen M aydınlatma sınıfı belirlenir.

$$
M x=6-V x
$$

Tablo 2. Değişik yol aydınlatma sınıflarında sağlanması gereken yol aydınlatması kriterleri (Road Lighting criteria for different road lighting classes) [12]

\begin{tabular}{|l|l|l|l|l|l|}
\hline $\begin{array}{c}\text { Aydınlatma } \\
\text { sınıfı }\end{array}$ & $\begin{array}{c}\text { Lort } \\
\geq\end{array}$ & $\mathbf{U}_{\mathbf{0}} \geq$ & $\mathbf{U}_{\mathbf{I}} \geq$ & $\begin{array}{c}\text { TI } \\
\mathbf{( \% )} \\
\leq\end{array}$ & $\mathbf{S R} \geq$ \\
\hline M1 & 2.0 & 0.4 & 0.7 & 10 & 0.5 \\
\hline M2 & 1.5 & 0.4 & 0.7 & 10 & 0.5 \\
\hline M3 & 1.0 & 0.4 & 0.5 & 10 & 0.5 \\
\hline M4 & 0.75 & 0.4 & 0.5 & 15 & 0.5 \\
\hline M5 & 0.5 & 0.35 & 0.4 & 15 & 0.5 \\
\hline M6 & 0.3 & 0.35 & 0.4 & 15 & - \\
\hline
\end{tabular}

Tablo 2'de yer alan kısaltmalar aşağıda açıklanmıştır;

$\mathrm{L}_{\mathrm{o}}$ : Yolun ortalama pariltısı $\left(\mathrm{cd} / \mathrm{m}^{2}\right)$

$\mathrm{U}_{\mathrm{o}}$ : Ortalama parıltı düzgünlük değeri $\left(\mathrm{U}_{\mathrm{o}}=\mathrm{L}_{\min } / \mathrm{L}_{\text {ort }}\right)$

$\mathrm{U}_{1}$ : Boyuna parıltı düzgünlük değeri $\left(\mathrm{U}_{\mathrm{l}}=\mathrm{L}_{\min } / \mathrm{L}_{\text {maks }}\right)$

$\mathrm{TI}:$ Bağıl eşik artışı $\left(\mathrm{TI}=\left\{\Delta \mathrm{L}_{\mathrm{K}}-\Delta \mathrm{L}_{\mathrm{e}}\right\} / \Delta \mathrm{L}_{\mathrm{e}}\right)$

SR: Çevreleme oranı (Yolun enine sınırları göz önüne alınarak yolun dışındaki aydınlık düzeyinin yolun içindeki aydınlık düzeyine oranıdır.)

Tablo 3. Yolların aydınlatma sınıflarının belirlenmesi (Determination of lighting classes of roads) [12]

\begin{tabular}{|c|c|}
\hline Yolun tanımı & $\begin{array}{l}\text { Ayd. } \\
\text { Sinıfi }\end{array}$ \\
\hline $\begin{array}{l}\text { Şehir bağlantı ve çevre yolları (tek veya iki } \\
\text { yönlü, kavşaklar ve bağlantı noktaları ile } \\
\text { şehir geçişleri dahil) } \\
\text { - } H_{1 z} \geq 90 \mathrm{~km} / \mathrm{h} ; \\
\text { - } \mathrm{H}_{1 \mathrm{z}}<90 \mathrm{~km} / \mathrm{h} ;\end{array}$ & $\begin{array}{l}\text { M1 } \\
\text { M2 }\end{array}$ \\
\hline $\begin{array}{l}\text { Şehir içi ana güzergahlar (bulvarlar ve } \\
\text { caddeler ; ring yolları ; dağıtıcı yollar) } \\
\text { - } 50 \mathrm{~km} / \mathrm{h} \leq \mathrm{H} ı \mathrm{z}<90 \mathrm{~km} / \mathrm{h} ; 3 \mathrm{~km} \text { ' den kısa } \\
\text { aralıklarla kavşak, yonca ayrımı var; } \\
\text { - } 50 \mathrm{~km} / \mathrm{h} \leq \mathrm{H} ı \mathrm{z}<90 \mathrm{~km} / \mathrm{h} ; 3 \mathrm{~km} \text { ' den kısa } \\
\text { aralıklarla kavşak, yonca ayrımı yok; } \\
\text { - Hız }<50 \mathrm{~km} / \mathrm{h} \text {; }\end{array}$ & $\begin{array}{l}\text { M1 } \\
\text { M2 } \\
\text { M3 }\end{array}$ \\
\hline $\begin{array}{l}\text { Şehir içi yollar (yerleşim alanlarına giriş } \\
\text { çıkışın yapıldığı ana yollar ve bağlantı } \\
\text { yolları) } \\
\text { - Hız } \geq 50 \mathrm{~km} / \mathrm{h} ; 3 \mathrm{~km} \text { ' den kısa aralıklarla } \\
\text { kavşak, yonca ayrımı var; } \\
\text { - Hız } \geq 50 \mathrm{~km} / \mathrm{h} ; 3 \mathrm{~km} \text { ' den kısa aralıklarla } \\
\text { kavşak, yonca ayrımı yok; } \\
\text { - Hız }<50 \mathrm{~km} / \mathrm{h} ; 3 \mathrm{~km} \text { den kısa aralıklarla } \\
\text { kavşak, yonca ayrımı var; } \\
\text { - Hız }<50 \mathrm{~km} / \mathrm{h} ; 3 \mathrm{~km} \text { ' den kısa aralıklarla } \\
\text { kavşak, yonca ayrımı yok; }\end{array}$ & $\begin{array}{l}\text { M3 } \\
\text { M4 } \\
\text { M4 } \\
\text { M5 }\end{array}$ \\
\hline $\begin{array}{l}\text { Yerleşim (ikametgah) bölgelerindeki yollar } \\
\text { - } 30 \leq \mathrm{H} 1 \mathrm{z}<50 \mathrm{~km} / \mathrm{h} ; \text { suç oranı yüksek; } \\
\text { - } 30 \leq \mathrm{H} 1 \mathrm{z}<50 \mathrm{~km} / \mathrm{h} \text {; suç oranı normal; } \\
\text { - } \mathrm{H} 1 \mathrm{z}<30 \mathrm{~km} / \mathrm{h} ; \text { suç oranı yüksek; } \\
\text { - } \mathrm{H}_{1 \mathrm{z}}<30 \mathrm{~km} / \mathrm{h} \text {; suç oranı normal; }\end{array}$ & $\begin{array}{l}\text { M4 } \\
\text { M5 } \\
\text { M5 } \\
\text { M6 }\end{array}$ \\
\hline
\end{tabular}

Tablo 3'te Türkiye şehir içi yol tanımları ve bu tanımlara uygun aydınlatma sınıfları verilmiştir.

IEC 60598-1 standardına göre $M$ ve $C$ sinıfı yollara ait armatürler IP65 veya daha yüksek korumaya, P sınıfı yollara ait armatürler ise IP55 veya daha yüksek korumaya sahip olmalıdır. 
EN 13201-2'ye göre yol aydınlatmas1 parılt1 düzeyine göre yol yüzeyinin kuru olduğu durumlar için altı sınıftan oluşan "ME" ve yol yüzeyinin nemli veya islak olduğu durumlarda "MEW" olarak sınıflandırılmıştır. ME6 yaya yolu, bisiklet yolu veya emniyet şeridi gibi anayolun bitişiğindeki bir şeridin asgari parlaklı̆̆ını kontrol eder.

ME sinıfları bölgelerde parlaklık $0.3-2 \mathrm{~cd} / \mathrm{m}^{2}$ aralığında değişmektedir. Aydınlık düzeylerine göre "CE", "S" ve "A", "ES", "EV" olarak sinıflandırılmaktadır.

CE sınıfları alışveriş alanları gibi karmaşı kavşaklarda, trafik araç kuyruklarının fazla olduğu yerlerde ayrıca yayalar ve bisikletliler ile de ilgilidir. Yoldaki gereksinimlere göre 7.5-50 lux aralığında yatay düzlem aydınlatmalarıyla sınıflandırılmıştır.

S ve A sinıfları yaya yolları, bisiklet yolları, emniyet şeritleri gibi alanlara ilişkindir. S sınıfları 215 lux yatay düzlem aydınlığını belirtirken, A sınıfları 1-5 lux yarı küresel aydınlık düzeyini belirtmektedir.

ES sınıfı, suç ihtimalinin normalden fazla olduğu yollarda nesnelerin ve insanların görünmesi için gerekli ek sınıflardandır. Yarı silindirik aydınlık düzeyi sınıfları 0.5-10 lux aralığındadır.

EV sınıfi, yol üzerinde gişe gibi geçiş bölgelerinde, kavşak alanlarında görülmesi gereken dikey yüzeyler için gerekli ek sinıftır. Dikey düzlemsel aydınlık düzeyi sinıfları $0.5-50$ lux aralığındadır.
Tablo 4. Aydınlatma sınıflarının karşılaştırılması (Comparison of lighting classes) [13]

\begin{tabular}{|c|c|c|c|c|c|}
\hline \multicolumn{2}{|r|}{ ME } & \multicolumn{2}{|c|}{ CE } & \multicolumn{2}{|c|}{$\mathbf{S}$} \\
\hline $\begin{array}{l}\text { Sinı } \\
\text { flar }\end{array}$ & $\begin{array}{c}\text { Parlaklık( } \\
\left.\mathbf{c d} / \mathbf{m}^{2}\right)\end{array}$ & $\begin{array}{l}\text { Sinı } \\
\text { flar }\end{array}$ & $\begin{array}{l}\text { Aydınl } \\
\text { lk(lx) }\end{array}$ & $\begin{array}{l}\text { Sinı } \\
\text { flar }\end{array}$ & $\begin{array}{c}\text { Aydınl } \\
\text { lk(lx) }\end{array}$ \\
\hline- & - & CE0 & 50 & - & - \\
\hline $\begin{array}{l}\text { ME } \\
1\end{array}$ & 2.0 & CE1 & 30 & - & - \\
\hline $\begin{array}{l}\text { ME } \\
2\end{array}$ & 1.5 & CE2 & 20 & - & - \\
\hline $\begin{array}{l}\text { ME } \\
3\end{array}$ & 1.0 & CE3 & 15 & S1 & 15 \\
\hline $\begin{array}{l}\text { ME } \\
4\end{array}$ & 0.75 & CE4 & 10 & S2 & 10 \\
\hline $\begin{array}{l}\text { ME } \\
5\end{array}$ & 0.5 & CE5 & 7.5 & S3 & 7.5 \\
\hline $\begin{array}{l}\text { ME } \\
6\end{array}$ & 0.3 & - & - & S4 & 5.0 \\
\hline- & - & - & - & S5 & 3.0 \\
\hline- & - & - & - & S6 & 2.0 \\
\hline
\end{tabular}

Tablo 4'te farklı aydınlatma sınıflarının parametrelerine göre karşılaştırılması verilmiştir.

\section{AYDINLATMA ARMATÜRLERİ (LIGHTING FIXTURES)}

Ülkemizde sokak aydınlatmaları için mevcut durumda içerisinde yüksek basınçlı sodyum buharlı (YBSB) lambalar bulunan geleneksel aydınlatma armatürleri kullanılmaktadır.

Yüksek basınçlı sodyum buharlı lambalar yüksek ışık verimine sahip olsa da lamba bir aydınlatma aygıtı içerisinde dahil edildiğinde 1 şı verimine etki eden bazı kayıplar ortaya çıkmaktadır. Bunlardan birincisi balast kaybı olarak bilinen lambayı çalıştırmak için kullanılan ateşleyici içerisinde harcanan enerjidir. Bir diğeri ise armatür gövdesi içerisindeki yansıtıcı yüzeylerde oluşan ışık kaybıdır.

Örneğin; 150W güçte çalışan yüksek basınçlı sodyum buharlı lamba 15.000 lümen 1şık ürettiğinde bu $100 \mathrm{~lm} / \mathrm{W}$ 1şık verimi anlamına gelir ancak harici ateşleyici güç tüketimini arttırır ve ışı̆̆ın bir kısmı lambanın içerisine yerleştirildiği armatür içerisinde kaybolur. Bu da armatür geneli düşünüldüğünde 1 şık veriminin daha düşük olmasına sebep olur. 


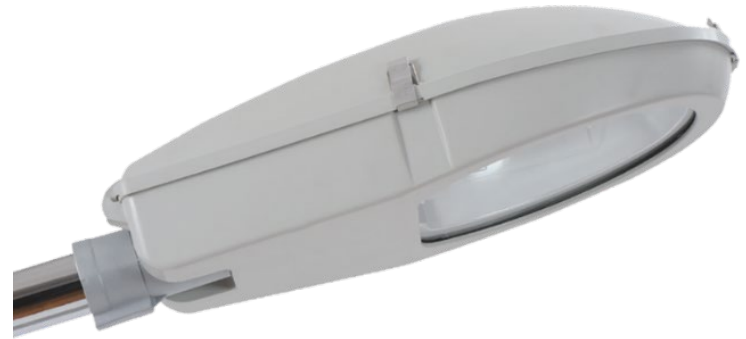

Resim 2. Yüksek basınçlı sodyum buharlı geleneksel aydınlatma armatürü (High pressure sodium vapor lighting fixture)

LED aydınlatma armatürlerinde ise, 1şık kaynağ ve LED sürücü armatür gövdesi içerisine gömülüdür. LED teknolojisiyle donatılmış aydınlatma armatürlerinde 1 şık çıktısı sistem olarak ölçülür ve kayıplar bu ölçüme dahil edilmiştir.

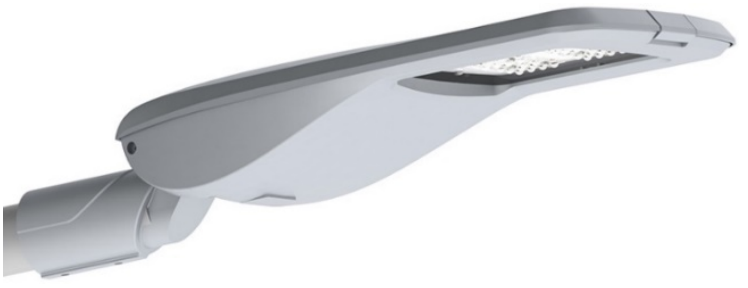

Resim 3. LED sokak aydınlatma armatürü (LED street lighting fixture)

Sokak aydınlatmalarında kullanılan farklı üreticilere ait yüksek basınçlı sodyum buharlı aydınlatma armatürleri ve LED aydınlatma armatürlerinin güç tüketimleri, 1şık çıktısı, etkinlik faktörü ve ekonomik ömrü Tablo 5 'te yer almaktadır.

Tablo 5. Farklı üreticilere ait aydınlatma armatürlerinin performans değerleri (Performance values of lighting fixtures from different manufacturers)

\begin{tabular}{|c|c|c|c|c|}
\hline $\begin{array}{l}\text { Işık } \\
\text { Kaynağı }\end{array}$ & $\begin{array}{l}\text { Güç } \\
\text { (W) }\end{array}$ & $\begin{array}{l}\text { Işık } \\
\text { Akısı } \\
\text { (lm) }\end{array}$ & $\begin{array}{l}\text { Etkinlik } \\
\text { Faktörü } \\
(\operatorname{lm} / \mathbf{W})\end{array}$ & $\begin{array}{l}\text { Ekonomik } \\
\text { Ömrü } \\
\text { (Saat) }\end{array}$ \\
\hline YBSB 1 & 168 & 10505 & 63 & \multirow{3}{*}{20.000} \\
\hline YBSB 2 & 175 & 12530 & 72 & \\
\hline YBSB 3 & 169 & 11824 & 66 & \\
\hline LED 1 & 100 & 13000 & 130 & \multirow{3}{*}{50.000} \\
\hline LED 2 & 100 & 12300 & 123 & \\
\hline LED 3 & 100 & 12100 & 121 & \\
\hline
\end{tabular}

Yukarıdaki tabloda görüldüğü üzere farklı üreticilere ait $100 \mathrm{~W}$ güç tüketimine sahip LED armatürler, 168-175W güç tüketimine sahip YBSB aydınlatma armatürleri ile benzer 1 şı çıtısı sunmaktadır. Bu durum birebir değişim senaryosunda aynı aydınlatma koşullarının sağlanması için 68-75W daha az enerji harcanacağı anlamına gelmektedir.

LED aydınlatma armatürlerinin bir diğer avantajı da daha uzun ekonomik ömre sahip olmasıdır. Işık kaynaklarında 1şık akısı, kullanımdan kaynaklı yüzde 30 azaldığında ekonomik ömrünü tamamladığı kabul edilir. YBSB lambalarda bu süre 20.000 saat iken LED 1şık kaynaklarında 50.000 saat ve üzerinde değerler elde edilebilmektedir.

LED aydınlatma dönüşümünde enerji tasarrufu sağlanır. Buna ek olarak LED'ler daha uzun ömürlü olduğundan lamba ve onarım maliyetlerinde de tasarruf sağlanır. Bunlar LED aydınlatma dönüşümünün başlıca faydalarıdır. Çalışmanın sonraki kısmında sokak aydınlatmalarında LED dönüşümünün fayda maliyet analizi gerçekleştirilecektir.

\section{FAYDA MALIYET ANALIZİ (COST BENEFIT ANALYSIS)}

Çalışmanın bu kısmında, Türkiye'de 2023 yılına kadar gerçekleştirilmesi planlanan 2.25 milyon sokak lambasının LED ile dönüşümünün 5 yıl için fayda maliyet analizi gerçekleştirilecektir.

Fayda maliyet analiz için yatırımdan elde edilecek fayda ve tasarruflar ile projenin gerçekleştirilmesi için yapılacak yatırım ayrı ayrı nakit akış diyagramlarında gösterilmelidir.

Yapılacak analiz sonrasında fayda maliyet oranı 1'den küçükse projenin yapımı reddedilir. Fayda maliyet oranı 1'den büyükse yatırımın gerçekleştirilmesi uygun olduğu sonucuna varılır.

Mevcut sokak aydınlatmalarının LED aydınlatma dönüşümünde toplam maliyet ürün bedeli ve montaj maliyetinin toplamından oluşur. Farklı üreticilere ait 5 yıl garanti ile sunulan $100 \mathrm{~W}$ güç tüketimine sahip LED sokak armatürlerinin fiyatları aşağıdaki tabloda gösterilmiştir.

Tablo 6. Farklı üreticilere ait LED sokak armatürü fiyatlar1 (LED street light prices from different manufacturers)

\begin{tabular}{|l|l|}
\hline Ürün Adı & Ürün Fiyatı (f) \\
\hline 100W LED Sokak Armatürü 1 & 490 \\
\hline 100W LED Sokak Armatürü 2 & 545 \\
\hline 100W LED Sokak Armatürü 3 & 520 \\
\hline
\end{tabular}


Hesaplamalarda yukarıdaki tabloda gösterilen farklı üreticilere ait aydınlatma armatürlerinin ortalama maliyeti olan 518 TL baz alınacaktır. Montaj maliyeti ise armatür başına 30 TL olarak hesaplanacaktır.

İşletme giderleri ise aydınlatma elemanından kaynaklı enerji tüketimi, lamba arızalarından kaynaklı lamba bedeli ve onarım maliyetinden oluşur.

Tablo 7. YBSB ve LED aydınlatma armatürlerinin güç tüketimi karşılaştırması (Power consumption comparison of MIS and LED lighting fixtures)

\begin{tabular}{|l|l|l|l|}
\hline $\begin{array}{l}\text { YBSB'li } \\
\text { Armatür } \\
\text { Güç } \\
\text { Tüketimi } \\
(W)\end{array}$ & $\begin{array}{l}\text { Eşdeğer } \\
\text { LED } \\
\text { Armatür } \\
\text { Güç } \\
\text { Tüketimi } \\
\text { (W) }\end{array}$ & $\begin{array}{l}\text { Güç } \\
\text { Tasarrufu } \\
\text { Miktarı } \\
\text { (W) }\end{array}$ & $\begin{array}{l}\text { Tasarruf } \\
\text { Yüzdesi }\end{array}$ \\
\hline 168 & 100 & 68 & $\% 40,48$ \\
\hline 175 & 100 & 75 & $\% 42,86$ \\
\hline 169 & 100 & 69 & $\% 40,83$ \\
\hline
\end{tabular}

Çalışmaya konu 3 farklı üreticiye ait YBSB lambalı aydınlatma armatürlerinin eşdeğeri LED aydınlatma armatürleri ile güç tüketimi karşılaştırması Tablo 7'de verilmiştir. Işık kaynağı olarak LED teknolojisinden yararlanan LED armatürler aynı miktarda 1şığı üretmek için geleneksel armatürler olan YBSB'li armatürlere göre yüzde 40-42 oranında daha az enerji harcamaktadır.

TEDAŞ (Türkiye Elektrik Dağıtım Anonim Şirketi) tarafından yayınlanan "Aydınlatma Mobil Takip Uygulaması" ile sokak lambalarının arızaları takip edilebilmektedir. TEDAŞ'ın verilerine göre 2019'un ilk 6 ayında 166 bin lamba onarılmıştır [14]. $\mathrm{Bu}$ da her yıl en az 332 bin lamba ve onarım maliyetinin ortaya çıktığııı göstermektedir.

Türkiye'de yaklaşık 7,5 milyon sokak lambası olduğu bilinmektedir. 6 ay içerisinde 166 bin lamba onarıldığı için yıllık hata oranı yüzde 4,43 olarak hesaplanabilir. 2.25 milyon sokak lambasının LED dönüşümünün fayda maliyeti hesaplanmas1 istendiğinden bu armatürlerde her yıl yüzde 4,43 oranla ortaya çıkan lamba bedeli ve onarım maliyeti sağlanacak fayda bölümünde yer almalıdır.
Mevcut durumda kullanılan 168W-175W güç tüketimine sahip sodyum buharlı armatürler yerine 100W LED armatürler kullanıldığında yaklaşık olarak yüzde 40 diğer bir deyişle $70 \mathrm{~W}$ daha az güç harcanacaktır. Bu da 2,25 milyon sokak armatürü için toplamda 157,5 MWh az enerji harcanması demektir. Ayda 30 gün ve günlük ortama 10 saat kullanımda ortaya çıkacak yıllık tasarruf miktarı Tablo 8'de gösterilmiştir.

Sodyum buharlı armatürlerde lamba bedeli yaklaşık olarak 23 TL'dir. İşçilik ve arıza bölgesine ulaşımı kapsayan onarım maliyeti ise yaklaşık olarak 30 TL'dir. Bu maliyetler toplam armatür sayısı ve hata oranıyla çarpılarak Tablo 8'deki veriler elde edilmiştir.

Türkiye Cumhuriyet Merkez Bankası (TCMB)'nin 2020 ve 2021 yılları için enflasyon hedefi yüzde 5'tir. Enflasyon hedefleri 3 'er yıllık dönemler halinde belirtildiğinden 2022, 2023 yılları için bir değerlendirme henüz yapılmamıştır. $\mathrm{Bu}$ sebeple dördüncü ve beşinci yıllar için de enflasyon oranı yüzde 5 olarak hesaplanacaktır.

Tablo 8. Enerji tüketimi, lamba bedeli ve onarım maliyetinden kaynaklı tasarruf miktarı (Savings from energy consumption, lamp costs and repair costs)

\begin{tabular}{|l|l|l|l|l|l|}
\hline \multirow{2}{*}{ Fayda } & \multicolumn{5}{|c|}{ Tasarruf Miktarı (f) } \\
\cline { 2 - 6 } & $1 . Y 11$ & $2 . Y_{1} 1$ & $3 . Y 11$ & $4 . Y 11$ & $5 . Y 11$ \\
\hline \multirow{2}{*}{ Enerji } & 306.1 & 321.4 & 337.56 & 354.4 & 372.1 \\
Tüketimi & 80.00 & 89.00 & 3.450 & 3.62 & 63.70 \\
& 0 & 0 & & 4 \\
\hline Lamba & 2.292 & 2.407. & 2.527. & 2.653. & 2.786 \\
Bedeli & .525 & 151 & 509 & 884 & .578 \\
\hline Onarım & 2.990 & 3.139. & 3.296. & 3.461. & 3.634 \\
Maliyeti & .250 & 763 & 751 & 588 & .668 \\
\hline \multirow{3}{*}{ Toplam } & 311.4 & 327.0 & 343.38 & 360.5 & 378.5 \\
& 62.77 & 35.91 & 7.710 & 57.09 & 84.95 \\
5 & 4 & 5 & 0 \\
\hline
\end{tabular}

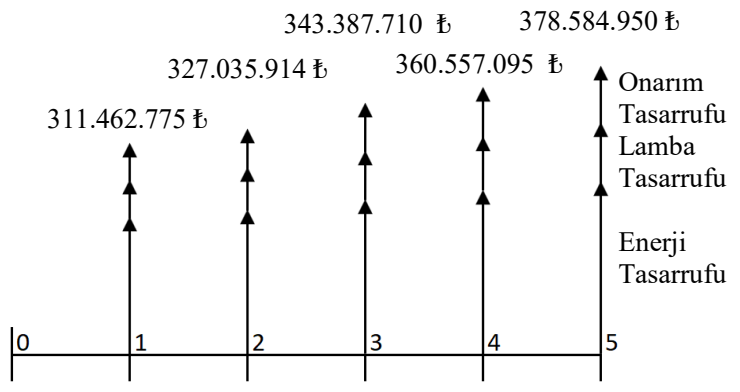

Şekil 1. Faydanın nakit akış diyagramı (Cash flow diagram of benefit) 
Sokak aydınlatmalarında yapılacak LED dönüşümünde ortaya çıkacak maliyet ürün bedeli, montaj maliyeti ve onarım maliyetidir. LED'ler uzun ömürlü 1şık kaynaklarıdır, herhangi bir bakım ya da onarıma ihtiyaç duymaz. Üreticiler de LED sokak armatürleri için 5 y1l garanti sunabilir. Ancak LED sokak armatürleri kullanıldıkları sürece bazı arızalar ortaya çıkabilir.

Kanada Ulaştırma Daimi Komitesi tarafından yayınlanan raporda 2014 yılında başlatılan 43.000 sokak armatürünün LED dönüşümüyle ilgili değerlendirmeler yapılmıştır. Raporda, LED sokak armatürlerinin yıllık hata oranının yüzde 1 ile yüzde 2 arasında olduğu belirtilmiştir. Arızaların çoğunun LED 1şı kaynağı yerine bu kaynağı besleyen elektronik kontrol modülünden (sürücü) kaynaklandığı tespit edilmiştir [15].

Arıza durumunda yeni sürücü devresi veya ürün değişimi için yeni ürün üretici tarafından garanti kapsamında sağlanacaktır. Ancak yine de mevcut sokak armatürünün veya armatür içerisindeki sürücünün değişimi için bir onarım maliyeti ortaya çıkacaktır. Yıllık yüzde 2 hata oranına göre ortaya çıkacak bu maliyet de maliyet tablosu ve akış diyagramına eklenmelidir.

Tablo 9. Ürün bedeli ve montaj maliyeti (Product cost and installation cost)

\begin{tabular}{|l|l|}
\hline Maliyet & Toplam Maliyeti (f) \\
\hline Ürün Bedeli & 1.165 .500 .000 \\
\hline Montaj Maliyeti & 67.500 .000 \\
\hline
\end{tabular}

Tablo 10. Arızalardan kaynaklı ortaya çıkacak yıllık onarım maliyeti (Annual repair costs due to malfunctions)

\begin{tabular}{|l|l|l|l|l|l|}
\hline \multirow{2}{*}{$\begin{array}{l}\text { Mali } \\
\text { yet }\end{array}$} & \multicolumn{4}{|l|}{ Toplam Maliyeti (f) } \\
\cline { 2 - 6 } & 1. Y11 & 2. Y11 & 3. Y11 & 4. Y11 & 5. Y11 \\
\hline $\begin{array}{l}\text { Onar1 } \\
\mathrm{m}\end{array}$ & $\begin{array}{l}1.350 . \\
\text { Maliy } \\
\text { eti }\end{array}$ & $\begin{array}{l}1.417 . \\
500\end{array}$ & $\begin{array}{l}1.488 . \\
375\end{array}$ & $\begin{array}{l}1.562 . \\
794\end{array}$ & $\begin{array}{l}1.640 . \\
933\end{array}$ \\
\hline
\end{tabular}

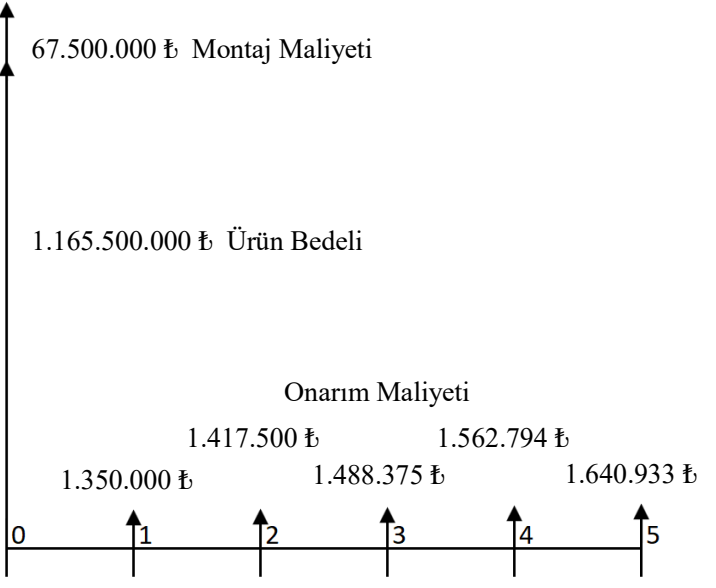

Şekil 2. Maliyetin nakit akış diyagramı (Cash flow diagram of cost)

Maliyet $=$ Ürün Bedeli + Montaj Maliyeti + Onarım Maliyeti $=1.165 .500 .000 £+67.500 .000 £+$ $5 \times 1.350 .000=1.239 .750 .000 €$

Fayda hesaplamasında sağlanan faydalar yatırımın yapıldığı yıla indirgenmiştir. Bu sebeple toplam fayda yıllık enflasyon etkisinde arındırılmış 5 yıllık toplamdir.

Fayda $=311.462 .775 € \times 5=1.557 .313 .875 €$

Fayda/Maliyet $=1.557 .313 .875 / 1.239 .750 .000=$ $1,26>1$ olduğu için projenin yatırımı uygundur.

\section{SONUÇ VE ÖNERILER (CONCLUSIONS AND RECOMMENDATIONS)}

LED teknolojisi ile geliştirilmiş sokak armatürleri yüksek 1şık çıktısı ve uzun ömür beklentisiyle uzun yıllardır sokak aydınlatmaları için kullanılan yüksek basınçlı sodyum buharlı armatürlere göre iyi bir alternatiftir. Geçmişte yapılan çalışmalar böyle bir dönüşümü gereksiz bulsa da günümüzde artık LED teknolojisi daha verimli ve daha kararlı bir aydınlatma çeşidi haline gelmiştir.

En güncel LED aydınlatma çözümlerinin mevcut durumda kullanılan geleneksel aydınlatmalarla karşılaştırıldığı bu çalışmada; fayda maliyet analizi yapılarak sonucun 1 'den büyük olduğu yani 5 yıl içerisinde sağlanacak faydanın bugünkü değerinin maliyetin bugünkü değerinden daha büyük olduğu sonucuna varılmıştır. Dolayısıyla, ülkemizde gerçekleştirilmesi planlanan sokak aydınlatması dönüşümü için yapımı uygundur sonucuna varılabilir. 
LED sokak armatürlerinin sağladı̆̆ yalnızca enerji tüketimi, lamba bedeli ve onarım maliyeti ile sınırlı değildir. LED’ler yönlü 1 şık kaynakları olduğundan 1şı kirliliğinin de azaltılmasına yardımcı olmaktadır.

LED'ler uzun ömürlü $(50.000,60.000$ ya da 90.000 saat) olsa da bir sistem içerisine dahil edildiklerinde giriş gerilimi, sürüş akımı, sıcaklık gibi etkenlerle ömürlerinde düşüş görülebilir. Üreticiler de ürünlerin kullanım ömrü ve garanti süresini belirlerken bu gibi etkenleri göz önüne almaktadır. Sokak aydınlatması dönüşümünde üretici firmalardan daha uzun garanti süreleri $(8,10,12$ yil) talep edilebilir. $\mathrm{Bu}$ sayede sağlanacak fayda ve fayda maliyet oranı da artırılmış olacaktır.

Diğer bir taraftan LED sokak armatürlerinin kullanım sürelerini uzatmak için endüstri genelinde bir standardizasyon çalışması yapılabilir. LED modülleri ve elektronik kontrol tertibatı (LED sürücü) için standart bir arayüz (LED dizilerinin dağılımı, elektriksel özellikleri, ölçüleri, vida delikleri vb.) oluşturulursa aydınlatma armatürlerinin içerisinde kullanılan bileşenlerin tam değişebilirliği sağlanabilir. $\mathrm{Bu}$ sayede bir üretici tarafından sağlanan armatür içerisindeki LED modül veya LED sürücü arızalandığında başka bir üretici tarafından sağlanan parçalar ile onarımı yapılabilir. Bu yöntemle LED'leri dış etkenlerden koruyan ve çalışması için gerekli koşulları sağlayan armatür gövdesi uzun yıllar boyunca kullanılabilir.

\section{KAYNAKLAR (REFERENCES)}

[1] E. Yılmaz, İ. Şahin, N. Y. Kocadağ. "LED Işık Kaynaklı, Enerji Tasarruflu ve Yüksek Verimli Ofis Aydınlatma Armatürü Tasarımı" Gazi Mühendislik Bilimleri Dergisi (GMBD), 2019, 5(2), 138-150.

[2] M. Öztoprak, "LED Aydınlatma Dönüşümü Ulusal Enerji Verimliliği Eylem Planı'na Girdi," aydinlatma.org, Mar. 30, 2018. [Online]. Available: http://www.aydinlatma.org/led-aydinlatmadonusumu-ulusal-enerji-verimliligi-eylem-planinagirdi.html. [Accessed: Dec. 7, 2019].

[3] K. Yamada, T. Honda, "ROad - VEhicle Lighting Integration. A Study of the Phase I Roveli System," The 3rd International Conference on Vehicle Navigation \& Information Systems, 2-4 Sept. 1992, Oslo [Online]. Available: IEEE Xplore, https://ieeexplore.ieee.org. [Accessed: 15 Nov. 2019].
[4] S. Zalewski, "Concurrent Lighting System on Roads in Practice," Lighting Conference of the Visegrad Countries (Lumen V4), 13-16 Sept. 2016, Karpacz [Online]. Available: IEEE Xplore, https://ieeexplore.ieee.org. [Accessed: 15 Nov. 2019].

[5] F. Li, D. Chen, X. Song, Y. Chen, "LEDs: a Promising Energy-Saving Light Source for Road Lighting," Asia-Pacific Power and Energy Engineering Conference, 27-31 Mar. 2009, Wuhan [Online]. Available: IEEE Xplore, https://ieeexplore.ieee.org. [Accessed: 17 Nov. 2019].

[6] M. Oxley, "HIDing Light in the Landscape," outdoorilluminating.com, Mar. 2005. [Online]. Available:

http://outdoorilluminating.com/PDF/HIDingLightArt icle.pdf. [Accessed: 10 Nov. 2019].

[7] Burlington Department of Planning \& Zoning, "Design Review Guide: Outdoor Lighting," burlingtonvt.gov, 1999. [Online]. Available: https://www.burlingtonvt.gov/sites/default/files/PZ/D esign-Guides/DG-Lighting.pdf. [Accessed: 10 Nov. 2019].

[8] J. A. Puigarnau, "EU green public procurement criteria for road lighting and traffic signals," data.consilium.europa.eu, Dec. 21, 2018. [Online]. Available:

https://data.consilium.europa.eu/doc/document/ST15852-2018-INIT/en/pdf. [Accessed: Oct.28 , 2019].

[9] Muhammad M. A. S. Mahmoud, "Typical Economic Model for Calculating the Saving Norm of Replacement HPS Street Lighting by LED Fixtures in Access Road of Gas Production Company at GCC," 5th International Conference on Electrical and Electronic Engineering (ICEEE), 3-5 May 2018, Istanbul [Online]. Available: IEEE Xplore, https://ieeexplore.ieee.org. [Accessed: 25 Nov. 2019].

[10] E. Anthopoulou, L. Doulos, "The effect of the continuous energy efficient upgrading of LED street lighting technology: The case study of Egnatia Odos" Second Balkan Junior Conference on Lighting (Balkan Light Junior), 19-21 Sept. 2019, Plovdiv [Online]. Available: IEEE Xplore, https://ieeexplore.ieee.org. [Accessed: 1 Dec. 2019].

[11] Commission Internationale de l'Eclairage "CIE 115-2010: Lighting of Roads for Motor and Pedestrian Traffic," cie.co.at, 2010. [Online]. Available: http://www.cie.co.at/publications/lightingroads-motor-and-pedestrian-traffic. [Accessed: Nov. 8, 2019]. 
[12] "Yol Aydınlatma Armatürleri Teknik Şartnamesi TEDAŞ- MYD/95-009.B," tedas.gov.tr, 2008. [Online]. Available: http://www.tedas.gov.tr/sx.web.docs/tedas/tedas_arg e/docs/sartnameler/tedas_arge/TEDA\%C5\%9EMYD-95-009.B-10.05.2018.pdf. [Accessed: Nov. 12, 2019].

[13] Türk Standardları Enstitüsü "TS EN 13201-2 Standardı, Yol aydınlatması bölüm 2: Performans özellikleri”, 2016.

[14] N. Karanfil, "6 ayda 166 bin lamba onarıld1," hurriyet.com.tr, Sept. 5, 2019. [Online]. Available: http://www.hurriyet.com.tr/ekonomi/6-ayda-166-binlamba-onarildi-41321793. [Accessed: Dec. 2, 2019].

[15] B. Anguish, "Issues with New LED Streetlights," halifax.ca, Feb. 25, 2019. [Online]. Available: https://www.halifax.ca/sites/default/files/documents/ city-hall/regional-council/190326rci01.pdf.

[Accessed: Dec. 5, 2019].

\section{Emre YILMAZ}

Emre Y1lmaz, 1990 y1lında Trabzon‘da dünyaya gelmiştir. Atılım Üniversitesi, Elektrik Elektronik Mühendisliği bölümü Lisans mezunudur. Gazi Üniversitesi, Endüstriyel Tasarım Mühendisliği bölümünde Yüksek Lisans öğrenimini tamamlamıştır, aynı bölümde Doktora yapmaktadır. Aydınlatma sektöründe devlet destekli projelerin yönetimi ve ürün geliştirme faaliyetlerinde görev almaktadır. Asya Trafik A.Ş. firmasında proje yöneticisi olarak çalışmaktadır. Türkiye'de aydınlatma sektörünün lider medya organizasyonu ve en büyük topluluğu olan Aydınlatma Portalı'nın kurucusudur. Aydınlatma Uygulamaları ve Aydınlatma Sözlüğü kitaplarının yazarıdır.

\section{Orhan ERDEN}

1969 yılında Ankara'da doğdu. Gazi Üniversitesi Endüstriyel San. Eğitim Fakültesi Endüstriyel Teknoloji Eğitimi Bölümü’nden 1991 y1lında mezun oldu. 1996 yılında yüksek lisansını, 2001 yılında doktorasını. Gazi Üniversitesi Fen Bilimleri Enstitüsü Endüstriyel Teknoloji Eğitimi Anabilim Dalında tamamladı. 1991-1996 yılları arasında öğretmenlik görevinde bulundu. Gazi Üniversitesi Endüstriyel San. Eğitim Fakültesi Endüstriyel Teknoloji Eğitimi Bölümü'nde 1996-2001 yılları arasında araştırma görevliliği yaptı, 2001-2009 yılında aynı bölümde Öğretim görevlisi olarak çalıştı. 2009-2017 yılları arasında Yardımcı Doçent Doktor görevinde bulundu. 2017 y1lından itibarende Gazi Üniversitesi Teknoloji Fakültesi, Endüstriyel Tasarım Mühendisliği Bölümü'nde Dr. Öğretim Üyesi olarak görevine devam etmektedir. Yurtiçi ve yurtdışında yayınlanmış çok sayıda yayını ve 2 kitabı bulunan Orhan ERDEN, evli ve 3 çocuk babasıdır.

\section{Nuri Yunus KOCADAĞ}

Nuri Yunus Kocadağ, 1991'de Ankara'da doğmuştur. Kırıkkale Üniversitesi, Elektrik Elektronik Mühendisliği bölümü 2013 yılı Lisans ve 2017 yılı Yüksek Lisans mezunudur. Bingöl Üniversitesi Teknik Bilimler MYO Elektrik ve Enerji bölümünde Öğretim Görevlisi olarak çalışmaktadır. 